\title{
Conformation and the Properties of Porcine Brain Calmodulin Incorporated in Liposomes
}

\author{
Yoshiyuki Kondo, Masatoshi NAOI, Toshihiro FUJII, \\ Hirotada FUJII,* and Kosuke OHKI** \\ Department of Functional Polymer Science, \\ Faculty of Textile Science and Technology, \\ Shinshu University, Ueda 386, Japan \\ * Tokyo Metropolitan Institute of Medical Science. \\ Hon Komagome, Bunkyo-ku, Tokyo 113, Japan \\ ** Department of Life Sciences, Konan Womens College, \\ Konan 483, Japan
}

(Received March 25, 1987)

\begin{abstract}
The conformation and properties of porcine brain calmodulin (CaM) in egg lecithin liposome were investigated by measuring fluorescence and circular dichrorism (CD). Two to five percent $\mathrm{CaM}$ could be incorporated into the unilamellar vecicles and the fluorescence emmision maximum of dancylated $\mathrm{CaM}$ was found to shift toward shorter wavelength by $20 \mathrm{~nm}$. In contrast, a capture efficiency of CaM in multilamellar vesicles was 10 to $30 \%$ and the $\alpha$-helical content of $\mathrm{CaM}$ increased with increasing lecithin concentration. In the absence of $\mathrm{Ca}^{2+}$ at the lecithin concentration of $5-10 \mathrm{mg} \mathrm{ml}^{-1}$, the $\mathrm{CD}$ spectrum suggested the same conformation for $\mathrm{CaM}$ which bound $\mathrm{Ca}^{2+}$. In the presence of $\mathrm{Ca}^{2+}$ at $1-2 \mathrm{mg} \mathrm{ml}^{-1}$ lecithin concentration, the $\mathrm{CD}$ spectrum indicated the destruction of $\alpha$-helical conformation, whereas, at $5-10 \mathrm{mg} \mathrm{m}^{-1}$ lecithin concentration, the $\mathrm{CD}$ spectrum was the same with that of $\mathrm{CaM}$ upon calcium binding. The results of CD measurements were supported by fluorescence spectra.

KEY WORDS CD / Fluorescence Spectra / Liposome / Porcine Brain Calmodulin / Conformation /
\end{abstract}

Recently, liposomes have been widely used as models of biomembranes, because these are small vesicles made from lipid lamellae in which ions and low molecular weight materials can be trapped depending on the size of water pools of liposomes. Furthermore, liposomes can encapsulate high molecular weight materials such as enzymes, and proteins and incorporation of lysozyme and serum albumin into liposomes was successfully reported. ${ }^{1,2}$ Therefore liposomes are considered to work as a carriers for such materials incorporated. ${ }^{3,4}$

However there are few studies on the nature of high molecular weight materials incorporated into liposomes such as their conformation and biological functions, although the dynamic properties of membranes of liposomes have been actively studied by NMR and ESR. ${ }^{5.6}$

In this study, conformational studies of $\mathrm{CaM}$, which is one of the $\mathrm{Ca}^{2+}$ receptors and is incorporated into liposomes made from egg phosphatidyl choline, were carried out. CaM is adequate for studying the conformational change between the aqueous media and liposomes, since its primary higher structure and $\mathrm{Ca}^{2+}$-binding site have been fully elucidated. ${ }^{7}$

Abbreviations: CaM, calmodulin; PIPES, piperazine- $N, N^{\prime}$-bis(2-ethanesulfonic acid). 
$\mathrm{CaM}$ was incorporated into unilamellar vesicles produced by ethanol injection method ${ }^{8}$ and reverse-phase evaporation technique (REV), ${ }^{9}$ and the results were compared with those in multilamellar vesicles.

\section{EXPERIMENTAL}

\section{Materials}

All chemicals were of high grade commercial products. CaM was isolated from porcine brain as previously described ${ }^{10}$ and dancylated according to the method of Johnson and Wittenauer. ${ }^{11}$ Egg lecithin was obtained from Asahikasei Co., Ltd.

\section{Preparation of CaM Incorporated in Lecithin Liposomes}

In all the experiments, $\mathrm{CaM}$ was dissolved into $10 \mathrm{mM}$ PIPES-KOH buffer so as to be incorporated into liposomes. The preparations of liposomes are briefly described below.

(1) Unilamellar vesicles: unilamellar vesicles were prepared by either of the following two methods.

(a) Ethanol injection method. ${ }^{8}$ Two volumes of egg lecithin dissolved in ethanol were added at the rate of $0.2 \mathrm{ml} \mathrm{min}^{-1}$ into one volume of $10 \mathrm{mM}$ PIPES-KOH buffer (pH 7.0).

(b) REV method. ${ }^{9}$ Three volumes of egg lecithin dissolved into diethyl ether were mixed with one volume of $10 \mathrm{mM}$ PIPES-KOH buffer $(\mathrm{pH} 7.0)$, and the unilamellar vesicles were produced by evaporating diethyl ether after sonication for $10 \mathrm{~min}$ at $23^{\circ} \mathrm{C}$ under $\mathrm{N}_{2}$.

(2) Multilamellar vesicles: Multilamellar vesicles were prepared by $10 \mathrm{~min}$ sonication at $23^{\circ} \mathrm{C}$ after adding $10 \mathrm{mM}$ PIPES-KOH buffer (pH 7.0) containing CaM to egg lecithin dissolved in chloroform.

\section{Fluorescence Measurements}

In the present study, dancylated $\mathrm{CaM}$ was used throughout the experiments. Fluorescence emission spectra were measured with a Hitachi 650-10S spectrofluorometer.
The emission spectra of dancylated $\mathrm{CaM}$ were recorded at an excitation wavelength of $340 \mathrm{~nm}$, and the spectra were corrected against the background spectra. The fluorescence intensity was the relative one against the intensity of dancylated $\mathrm{CaM}$ in an aqueous buffer.

\section{Circular Dichroism (CD) Measurements}

CD was measured with a JASCO J-40A automatic recording dichrograph at $23^{\circ} \mathrm{C}$. The cylindrical cells of $0.2 \mathrm{~mm}$ path length was used. The solvent used was $10 \mathrm{mM}$ PIPES$\mathrm{KOH}, \mathrm{pH} 7.0$.

\section{Gel Filtration Chromatography}

Chromatography of liposomes was carried out on Sepharose 4B which was equilibrated and developed with $10 \mathrm{mM}$ PIPES-KOH $(\mathrm{pH}$ 7.0) buffer. The absorbance at $410 \mathrm{~nm}$ and the fluorescence intensity at $490 \mathrm{~nm}$ excited at $340 \mathrm{~nm}$ were used to detect liposomes and dancylated $\mathrm{CaM}$, respectively, in the elution.

\section{RESULTS AND DISCUSSION}

\section{Gel Filtration Chromatography of Liposomes}

Figure 1 shows the elution profiles of liposomes containing $\mathrm{CaM}$ in their inner aqueous phase on Sepharose 4B column. ${ }^{12}$ In unilamellar liposomes prepared by ethanol injection method (Figure 1(a)), the elution peak for liposome did not coincide with that for CaM, but in the case of unilamellar liposomes prepared by REV method (Figure 1(b)), those two peaks eluted at the same position although the protein peak was small, indicating that some $\mathrm{CaM}$ molecules were incorporated into the unilamellar liposomes. The elution profile of multilamellar liposomes also showed fairly large peaks for liposomes and $\mathrm{CaM}$ at the same position, indicating that the capture efficiency of $\mathrm{CaM}$ was relatively high.

In order to evaluate the amount of $\mathrm{CaM}$ in multilamellar liposomes, free CaM molecules were expelled from liposomes suspensions by 
Conformation of Calmodulin in Liposomes

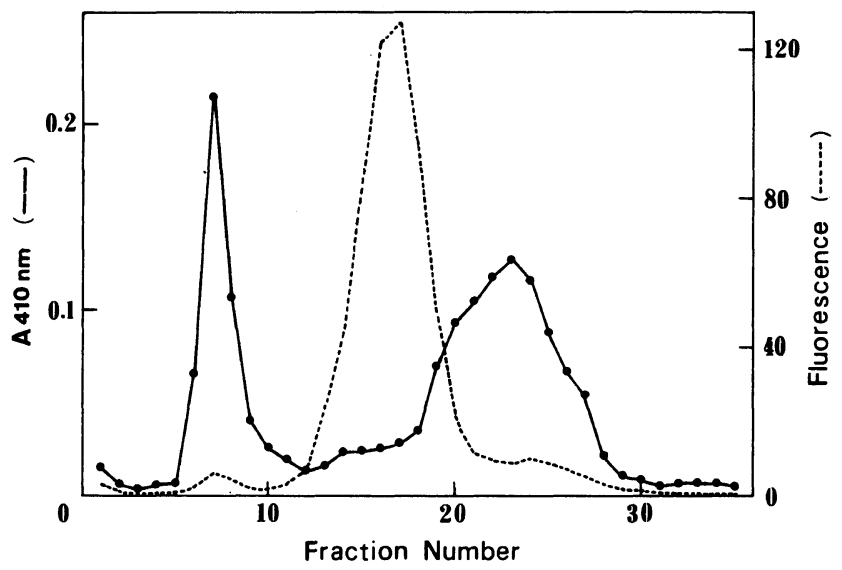

(a)

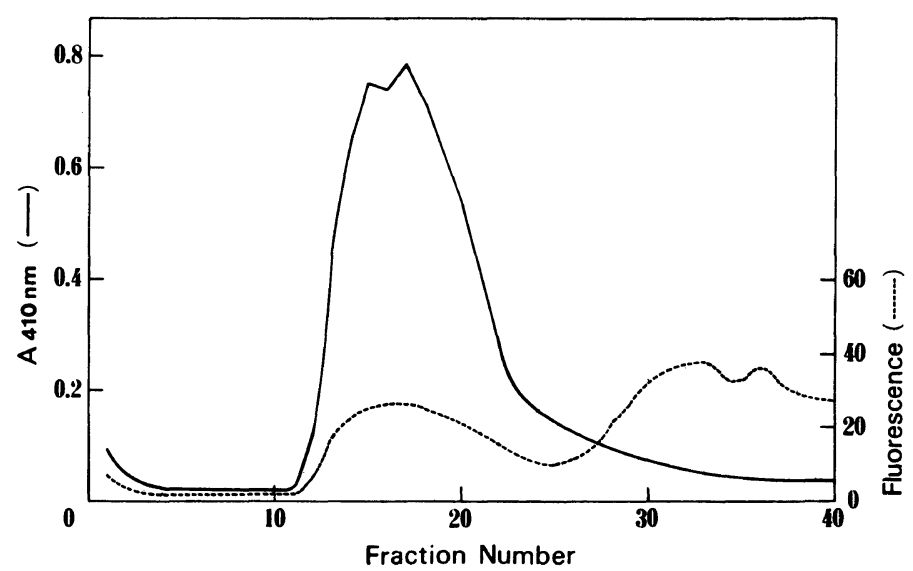

(b)

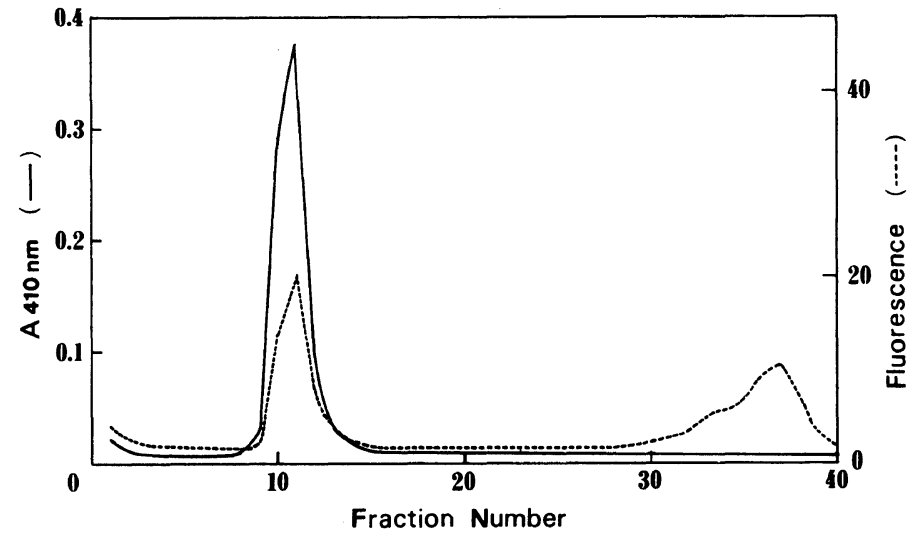

(c)

Figure 1. Gel filtration of liposomes on sepharos 4B. (a) Ethanol injection liposome. (b) Reverse-phase evaporation liposome. (c) Multilamellar liposome. (-), lipid determined by absorbance at $410 \mathrm{~nm}$; $(----), \mathrm{CaM}_{\text {Dans }}$ measured at $510 \mathrm{~nm}$. 

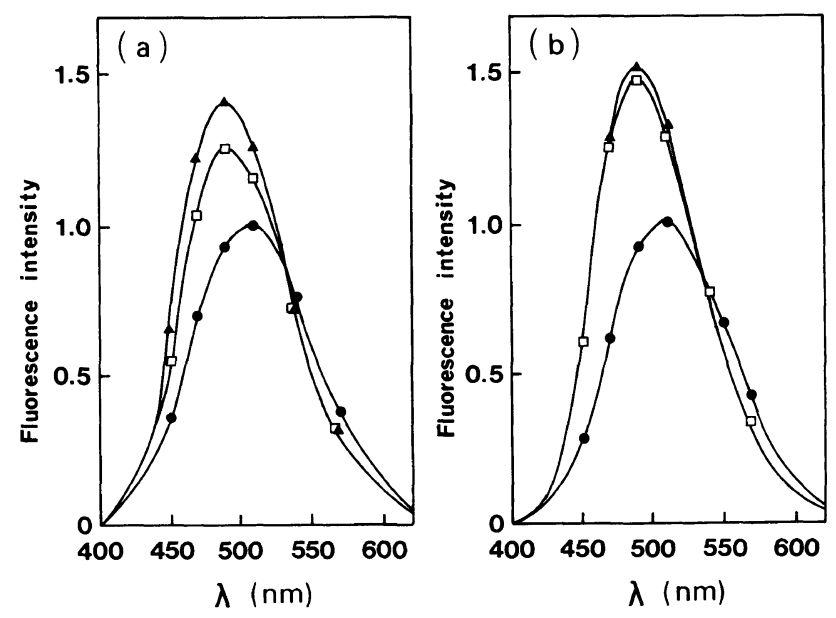

Figure 2. Fluorescence emission spectra of $\mathrm{CaM}_{\mathrm{DANS}}$ in ethanol injection liposomes (a) and in multilamellar liposomes (b): ( $\mathbf{\Delta}), \mathrm{CaM}$ in liposome in the presence of $\mathrm{Ca}^{2+} ;(\square), \mathrm{CaM}$ in liposome in the absense of $\mathrm{Ca}^{2+} ;(\bullet), \mathrm{CaM}$ in buffer solution (10 mM PIPES-KOH pH 7.8).

centrifugation at $100,000 \times g$ for $20 \mathrm{~min}$. The $\mathrm{CaM}$ concentration in a supernatant solution was determined by the method of Bradford et $a l .{ }^{13}$ By subtracting the amount of $\mathrm{CaM}$ in the supernatant from the initial amount of $\mathrm{CaM}$ in PIPES-KOH (pH 7.0) buffer, the capture efficiency was found to be about $30 \%$.

\section{Fluorescence Spectra of Dancylated CaM in Liposomes}

Figure 2(a) shows fluorescence spectra of dancylated CaM in unilamellar liposomes prepared by ethanol injection method. The fluorescence maximum of dancylated $\mathrm{CaM}$ in aqueous media was observed at $510 \mathrm{~nm}$, whereas it shifted to $490 \mathrm{~nm}$ in unilamellar liposomes. The fluorescence intensities of dancylated $\mathrm{CaM}$ in unilamellar liposomes also increased by $27 \%$ in the absence of $\mathrm{Ca}^{2+}$ and by $42 \%$ in its presence compared with the intensity in buffer solutions. In contrast, the fluorescence intensity of dancylated-CaM in a aqueous solution increased by $40 \%$ on addition of $\mathrm{Ca}^{2+}$. The fluorescence maximum of dancylated $\mathrm{CaM}$ in the multilamellar liposomes was also blue-shifted to $490 \mathrm{~nm}$, and the fluorescence intensity increased by $50 \%$ irrespective of the presence of $\mathrm{Ca}^{2+}$ (Figure 2(b)).
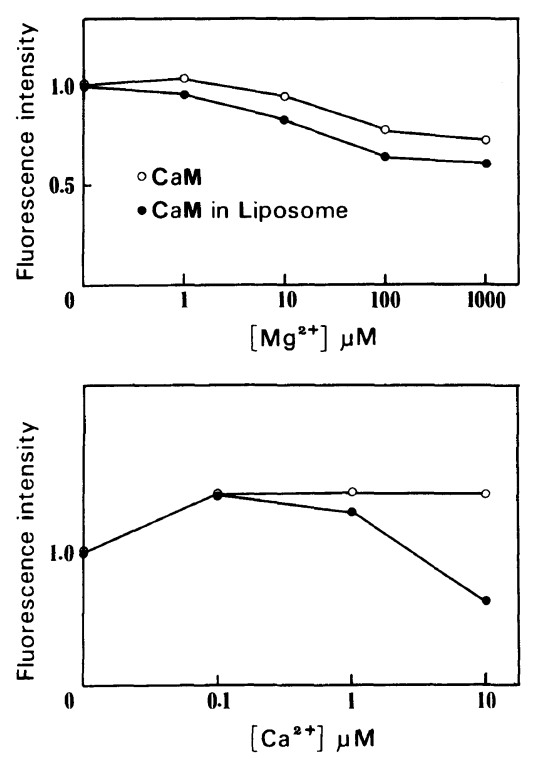

Figure 3. Effect of $\mathrm{Mg}^{2+}$ and $\mathrm{Ca}^{2+}$ on $\mathrm{CaM}$ fluorescence in multilamellar liposome.

When CaM was added to lecithin liposomes prepared by adding $\mathrm{CaM}$ to lecithinchloroform solution before the addition of the buffer, blue-shift and enhancement of the fluorescence spectra were observed.

The effect of the concentrations of $\mathrm{Ca}^{2+}$ and $\mathrm{Mg}^{2+}$ on dancylated-CaM fluorescence using 

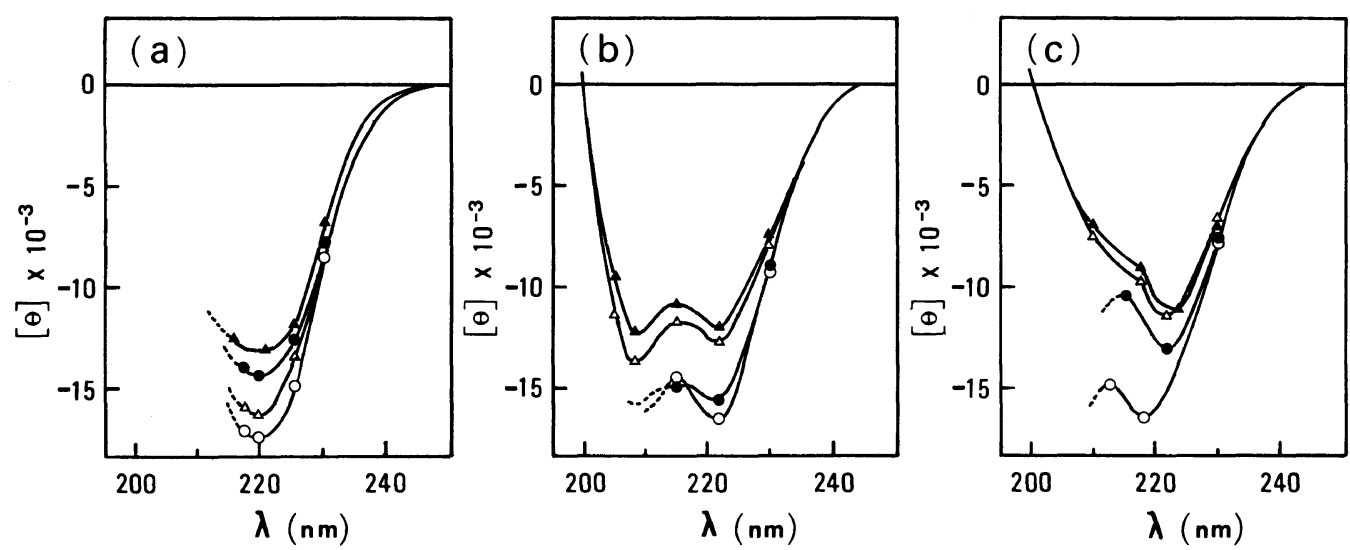

Figure 4. CD spectra of CaM. (a) In ethanol injection and reverse-phase evaporation liposomes: $(\boldsymbol{\Delta})$, CaM in ethanol injection liposome in the absence of $\mathrm{Ca}^{2+} ;(\triangle)$, in the presence of $\mathrm{Ca}^{2+} ;(\mathrm{O}), \mathrm{CaM}$ in reverse-phase evaporation liposomes in the absense of $\mathrm{Ca}^{2+} ;(\mathrm{O})$, in the presence of $\mathrm{Ca}^{2+}$. (b) Effect of multilamellar liposome in the absence of $\mathrm{Ca}^{2+}:(\mathbf{\Delta}),\left[\right.$ lecithin] $=1 \mathrm{mg} \mathrm{ml}^{-1} ;(\triangle), 2 ;(\bigcirc), 5 ;(\bigcirc), 10$. (c) Effect of multilamellar liposome in the presence of $\mathrm{Ca}^{2+}:(\Delta),[$ lecithin $]=1 \mathrm{mg} \mathrm{ml}^{-1} ;(\triangle), 2 ;(\bigcirc), 5 ;(\bigcirc)$, 10.

by multilamellar liposomes was studied (Figure 3). With increase of $\mathrm{Mg}^{2+}$ concentration, fluorescence intensity decreased gradually, and a noticeable difference was not observed with or without the liposomes. In contrast, over $10^{-5} \mathrm{M} \mathrm{Ca}^{2+}$, a remarkable decrease in fluorescence intensity was observed in the presence of liposomes. These results suggest that $\mathrm{Ca}^{2+}$ binds with $\mathrm{CaM}$ in unilamellar liposomes. On the other hand, it binds with a liposome membrane rather than with CaM in multilamellar liposomes, causing the decrease of membraneous fluidity and consequently the decrease of hydrophobicity in environment around CaM.

\section{Circular Dichroism Spectra of Liposomes}

CD spectra of the unilamellar liposomes containing CaM prepared by both methods of the ethanol injection and REV were shown in Figure 4(a). In the absence of $\mathrm{Ca}^{2+}$, both liposomes showed almost the same values of $[\theta]_{220}$ as that for CaM in aqueous solutions. In liposomes by REV method, the value of $[\theta]_{220}$ gave $-14,000$, indicating the $\alpha$-helix content was about $35 \%$ and was a little higher than
$31 \%$ in liposomes prepared by the ethanol injection method. This difference seems closely relate to the differences in the size of liposomes and the capability to get incorporate the aqueous solution into the liposomes. In general, the diameter of the liposomes prepared by REV is in the range of 200 to $1000 \mathrm{~nm}$, which is much larger than those prepared by the ethanol injection method, 30 to $110 \mathrm{~nm}$. The REV method can provide liposomes with higher entrapping efficiency than the ethanol injection method. This high entrapping efficiency seems to decrease the rate of contact surface between $\mathrm{CaM}$ and lipid, and accordingly $\mathrm{CaM}$ in liposomes prepared REV method resembles more that in aqueous solution. In the presence of $\mathrm{Ca}^{2+}$, the values of $[\theta]_{222}$ for CaM in liposomes prepared by the ethanol injection method and REV method were $-16,000$ and $-17,000$, respectively. These results suggest that on binding of $\mathrm{Ca}^{2+}, \mathrm{CaM}$ molecules take on the $\alpha$-helix enriched conformation.

The CD spectra of CaM incorporated into the multilamellar liposomes in the absence of $\mathrm{Ca}^{2+}$ were depicted in Figure 4(b) as a function of the concentration of the lipid. When 
the lipid concentration was $1 \mathrm{mg} \mathrm{ml}^{-1}$, the values of $[\theta]_{222}$ and $[\theta]_{208}$ were the same as those in the aqueous solution, indicating the $\alpha$ helix content of CaM molecules was $31 \%$. Figure 4(b) also shows that the magnitude of $\mathrm{CD}$ band increases as the lipid concentration increases from 2 to $5 \%$ although $C D$ below $212 \mathrm{~nm}$ could not be measured because of turbidity increment, indicating that lipid interacts directly with $\mathrm{CaM}$ and makes the CaM more stable by increasing the $\alpha$-helix content.

The same experiments were carried out in the presence of $\mathrm{Ca}^{2+}$, and the results are shown in Figure 4(c). At relatively low concentrations of the lipids ( 1 and $2 \mathrm{mg} \mathrm{ml}^{-1}$ ) the $\mathrm{CD}$ band at $222 \mathrm{~nm}$ was observed with the value of $-11,000$ to $-12,000$, but only the weak shoulder was observed at $210 \mathrm{~nm}$. This suggests that the destruction of $\alpha$-helical conformation and/or the increase of the $\beta$-structure of $\mathrm{CaM}$ molecules occurred by the interaction of $\mathrm{Ca}^{2+}$-lipid with CaM. As the lipid concentration increases up to $10 \mathrm{mg} \mathrm{ml}^{-1}$, the magnitude of $\mathrm{CD}$ band again increased and the values at $222 \mathrm{~nm}$ was $-17,000$, which was almost identical with that in the absence of $\mathrm{Ca}^{2+}$ and reveals that the $\alpha$-helical conformation turns out to be predominant. The fact that the CD spectra of multilamellar liposomes were almost identical between in the absence and presence of $\mathrm{Ca}^{2+}$ indicates that $\mathrm{Ca}^{2+}$ interactes with lipid but not with $\mathrm{CaM}$ in multilamellar liposomes as stated above.
From above the results, the following conclusions were obtained.

1) The conformation of $\mathrm{CaM}$ molecules incorporated into the unilamellar liposomes can be easily changed by $\mathrm{Ca}^{2+}$.

2) In the multilamellar liposomes, more CaM molecules were incorporated into liposomes than in unilamellar liposomes, and the conformation of $\mathrm{CaM}$ could be appreciably changed by increasing the lipid concentration.

\section{REFERENCES}

1. G. Sessa and G. Weissmann, J. Biol. Chem., 245, 3295 (1970).

2. G. Gregoriadis and B. E. Ryman, Eur. J. Biochem., 24, 485 (1972).

3. M. Finkelstein and G. Weissmann, J. Lipid. Res., 19, 289 (1978).

4. G. Gregoriadis and N. Engl, J. Med., 295, 704 (1976).

5. Y. K. Levine, N. J. M. Birdsall, A. G. Lee, and J. C. Metcalfe, Biochemistry, 11, 1416 (1972).

6. R. D. Kornberg and H. M. McConnell, Proc. Natl. Acad. Sci., U.S.A., 68, 2564 (1971).

7. S. Kakiuchi, H. Hidaka, and A. R. Means, Eds., "Calmodulin and Intracellular $\mathrm{Ca}^{2+}$ Receptors," Plenum Press, New York, N.Y., 1982.

8. S. Batzri and E. Korn, Biochem. Biophys. Acta, 298, 1015 (1973).

9. F. Szoka and D. Papahadjopoulos, Proc. Natl. Acad. Sci., U.S.A., 75, 4194 (1978).

10. Y. Kondo, M. Naoi, K. Koyama, T. Fujii, and K. Ohki, Kobunshi Ronbunshu, 42, 467 (1985).

11. J. D. Johnson and L. A. Wittenauer, Biochem. J., 211, 473 (1983).

12. C. H. Huang, Biochemistry, 8, 344 (1969).

13. M. Bradford, Anal. Biochem., 72, 248 (1976). 